\title{
PROCEDURE FOR CONSTRUCTING SOFT MODELS OF COMPLEX SYSTEMS BY TIME SERIES
}

\author{
S.I. Suyatinov, Bauman Moscow State Technical University, Moscow, \\ Russian Federation, ssi@bmstu.ru
}

The problem of creating models of complex systems for assessing their state is considered. The analysis of approaches to construction of diagnostic models is given and their features are marked. For a complex system with a hierarchical structure, a procedure for constructing the models to assess its state using a scalar time series is proposed. In this case, each hierarchical level is described by a lumped-parameter differential equation. The procedure is based on the concept of soft modelling. The efficiency of the proposed procedure is demonstrated by the example of constructing a model for assessing the state of a complex heart rhythm regulation system.

Keywords: complex system; soft modelling; basic models; cardiovascular system.

Dedicated to Professor T.B. Chistyakova on the occasion of her anniversary

\section{Introduction}

The mathematical formalization of a complex system is an important task in solving many problems in various subject areas [1-4]. The presence of an adequate model allows one to make reliable estimates of the state of a complex object and the forecast of its development. Depending on the availability of information about the properties of the system, various approaches to the development of its models are possible [5-8].

To describe well-structured systems, analysis methods are traditionally used. The methods consist in the sequential decomposition of the system into components and the development of models of ever simpler elements based on known laws. This approach is used, for example, in the design of complex technical objects [9-11].

In the absence of detailed information about the properties and reactions of the system to the known input effects, there is a problem of creating a model based on incomplete data (under uncertainty).

One of the approaches to solve this problem is the reconstruction of dynamic system equations from time series [12-14]. The structure of the model is set by a universal mathematical model without reference to the structure of the real object, and the parameters are determined by the recorded output signals in the form of time series.

Recently, neural networks have been widely used as a universal model structure [15, 16]. However, the structure of the neural network itself makes it difficult to assess the dynamics of the phase variables of the studied system, which reduces its prognostic and diagnostic value.

Various reconstruction methods are proposed and justified in nonlinear dynamics on the basis of Takens' theorem $[8,17,18]$. The system of differential equations with included nonlinearity is chosen as a universal mathematical structure. But such a model does not have the property of global stability and is characterized by numerous parameters that do 
not have physical meaning. In addition, a significant disadvantage of this approach is the need for multiple differentiation of the initial time series to estimate the parameters of the model.

In addition, in both cases, a priori information about the nature of dynamic processes, which can be identified from time series analysis or from other sources, remains unclaimed.

A priori information, in the case of its correct use, can improve the adequacy of the model structure and solve the problem of incorrect evaluation of its parameters.

The purpose of this article is to develop a procedure for constructing models of complex systems over time series based on a priori information.

\section{Simple Models of Complex Systems}

There are two ways to model representation of complex systems: microscopic and macroscopic approaches. The first approach involves construction of corresponding analytical models based on a detailed analysis of the functions of each part of the system. In the second case, the emphasis is on the effects of the collective behavior of all parts. Microscopic analysis of complex systems either leads to a system of differential equations of large dimension, or is generally impossible due to the lack of necessary information.

However, there are cases when a complex system at a macroscopic level shows a fairly simple behavior [19, 20]. First of all, this refers to complex systems that demonstrate an oscillatory character. It should be noted that in most practical cases, these systems have structural stability, i.e. keep the oscillatory mode with small changes in their parameters.

The indicated behavioral features of the selected class of systems allow us to use the concept of soft modelling [21-23] for their description, based on the synergetic paradigm. It postulates the existence of relatively simple basic models that describe oscillatory processes in various fields of knowledge. A classic example is the Van der Pol equation.

The choice and justification of the structure of basic models is carried out on the basis of well-known physical laws that underlie the functioning of the considered dynamic system. The parameters of the structural and functional models obtained in this way are determined on the basis of the recorded time series.

Next, we consider a class of systems that can be represented in the form of a hierarchy of the structure of connected functionally complete blocks. Moreover, each functional block is distinguished by its unique time of elementary processes occurring in it. Thus, in addition to functional, there is a temporary hierarchy in the considered class of systems. These limitations are inherent in most real control systems.

The procedure for creating a model consists of the following steps.

1. Based on a priori information, a generalized structure of a complex system is constructed in the form of related subsystems. The assumed nature of the relationships between the subsystems is specified.

2. Using the registered time series, the characteristic times of the processes in the selected subsystems are determined and, in accordance with them, the necessary length of the recorded time series is calculated.

3. The leading (setting) subsystem is distinguished, and the characteristic time of the processes in it is determined. 
4. Based on a priori information about the nature of functional subsystems, the structure of a suitable model is selected from the class of basic models that describe oscillatory processes and have structural stability.

5. Stability is investigated and critical parameters are determined for each model of the selected subsystem.

6. Parametric identification of all models is performed using regularization methods.

7. The state of the subsystems of a complex system is estimated by the parameters of their models.

The implementation of the proposed procedure is considered on the example of constructing a model to assess the state of a complex system of heart rate regulation.

\section{Generalized Structure of a Complex System}

The object of modelling is a complex system of blood flow regulation. From the standpoint of synergetics, such a system has a lot of degrees of freedom. However, in the process of natural evolution, several main degrees are distinguished, to which all the others are adjusted. Therefore, models of a limited composition of subsystems reflect the basic properties of the entire complex system.

From experimental observations it was found that in the frequency range from $0,095 \mathrm{~Hz}$ to 1,6 Hz there are four physiologically justified energy peaks in the spectrum of cardiocycle signals. This means that in a time scale approximately equal to one minute, there are four almost periodic oscillatory subsystems that provide blood flow regulation [20, 24]. Table 1 shows the frequencies whose physiology of origin is the most studied.

Table 1

Frequencies of oscillatory processes and functions of physiological subsystems

\begin{tabular}{|c|c|}
\hline Frequency $(\mathrm{Hz})$ & Physiological function \\
\hline 1 & Contraction of the heart muscle (heart activity) \\
\hline 0,2 & Respiratory activity \\
\hline 0,1 & Myogenic activity \\
\hline 0,03 & Neurogenic activity \\
\hline
\end{tabular}

The main frequency of the signal, which prevails in the signals of the cardiocycle (ECG, blood pressure, sphygmogram), is about $1,1 \mathrm{~Hz}$ and corresponds to the heart rhythm. The frequency range of $0,12-0,4 \mathrm{~Hz}$ is a well-known range of respiratory activity in physiology. The respiratory movements of the chest are quite rhythmic. Myogenic regulation leads to the fact that smooth muscle cells continuously respond to changes in intravascular pressure. The constant activity of the autonomic nervous system (neurogenic activity) serves to maintain the basic level of vascular interaction (the so-called tone).

The heart rate regulation system using the selected subsystems is shown in Fig. 1.

Fig. 1 shows that each physiological mechanism manifests itself as a separate almost periodic process, which we can observe at the macroscopic level. In an integrated form, the functioning of all these subsystems is reflected in the dynamics of vessels. The heart 


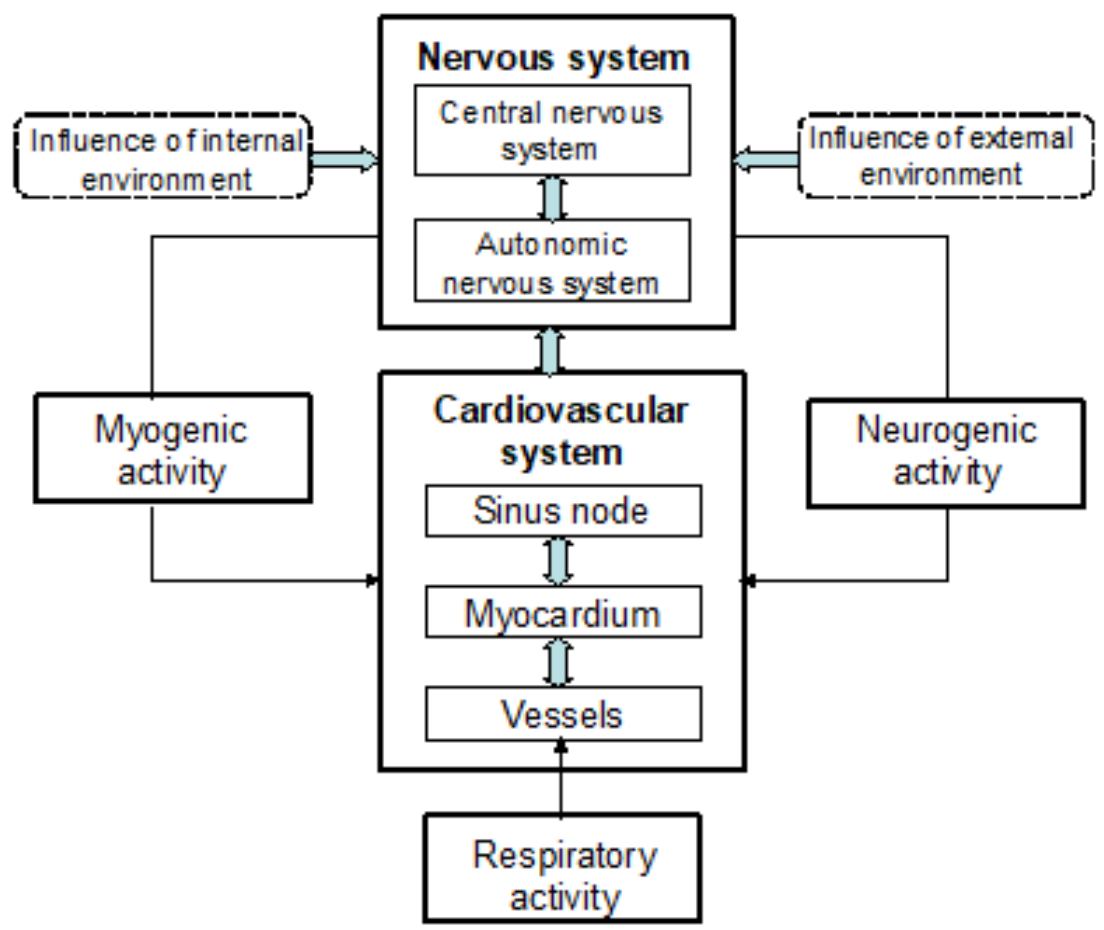

Fig. 1. The mechanisms of regulation of the cardiovascular system

and lungs form the input in the form of pressure, and the other two subsystems change the vascular tone. Therefore, we choose vessels as the main object of modelling.

Further, we believe that the oscillations observed in cardiac signals occur autonomously in each subsystem [25-27]. Then, mathematically, subsystems can be described by autonomous oscillators, and their contribution to the overall dynamics is additive. Therefore, in a first approximation, we assume that the relationships between the subsystems are linear.

To construct a model of cardiovascular regulation, the electrical activity of the heart (ECG), blood pressure in the artery and sphygmogram of the radial artery were simultaneously measured.

\section{Development of the Structure of Basic Models of Functional Subsystems Dynamics}

Since all the considered subsystems operate in the limit cycle mode, we will take equation (1) as the basic structure of the models, the parameters of which in the considered problem have obvious physical meaning:

$$
\ddot{x}+F(X) \cdot \dot{x}+a \cdot x=0 .
$$

Here $\omega_{0}=\sqrt{a}$ is the frequency of the fundamental harmonic oscillation, $F(X)$ is the oscillation attenuation coefficient, where $X$ is the vector of possible arguments of the function. From this equation, by setting the appropriate type of function, one can obtain various model equations, for example, Van der Pol or Rayleigh. The function $F(X)$ can be constructed on the basis of the features of the system. 
Several model equations are known that mathematically describe limit cycles. The Van der Pol equation is most commonly used. We use this equation as the structure of models of neurogenic and myogenic regulation.

A feature of the other two subsystems is their inertial character, which leads to a decrease in the amplitude of oscillations with increasing frequency. A combined model that takes this phenomenon into account is constructed using the equations of Van der Pol and Rayleigh together and has the form

$$
\ddot{x}+\left[\varepsilon_{1}\left(x^{2}-r_{0}^{2}\right)+\varepsilon_{2}\left(\dot{x}^{2}-\omega_{0}^{2} r_{0}^{2}\right)\right] \cdot \dot{x}+a x=0 .
$$

It should be especially noted that if the model of respiratory activity seems to be an autonomous generator, then the oscillations of the vessel walls occur under the influence of blood flow pressure. Given the filtering properties of the heart muscle, the current pressure is presented in harmonic form. The form of pressure on the walls of the vessel, taking into account the direct and reflected waves in the first approximation, take the form of a sinusoidal function with a frequency exceeding twice the frequency of pulse oscillations. Then the pulse dynamics model can be represented in the dimensionless form

$$
\ddot{x}+\left(\varepsilon_{1}\left(x^{2}-r^{2}\right)+\varepsilon_{2}\left(\dot{x}^{2}-\omega_{0}^{2} r^{2}\right)\right) \dot{x}+a x=F_{\text {connect }},
$$

where $x$ is the linear movement of the vessel wall; $r$ is the restriction on the movement of the vessel wall; $\omega_{0} r$ is the limitation of the speed of movement; $\varepsilon_{1}, \varepsilon_{2}\left(\varepsilon_{1}<0, \varepsilon_{2}<0\right)$ are the constant coefficients; $a$ is the parameter describing the stiffness (elasticity) of the vessel wall $(a>0) ; F_{\text {connect }}$ is the connection function describing blood flow pressure, $F_{\text {connect }}=b \cos 2 \omega t$.

Therefore, the procedure for identifying the structure of the model is completed. The resulting soft model of heart rate regulation has a hierarchical structure, the levels of which are determined by the values of the periods of characteristic oscillations of the subsystems. Models of neurogenic and myogenic activity are described by autonomous Van der Pol equations, while other models have a combined Van der Pol-Rayleigh structure, and the equation of dynamics of the vessel wall has a non-autonomous form.

At the next step, it is necessary to perform an analysis of the stability of periodic modes and determine the possible ranges of variation of model parameters.

\section{Stability Analysis of the Periodic Solution to Model Equations}

The stability analysis of periodic solutions is carried out according to the methodology presented on the example of the analysis of the dynamics model of the vessel wall.

The aim is to study the possible behavior of the model under variations of various parameters $a, b, r, \omega, \omega_{0}, \varepsilon_{1}, \varepsilon_{2}$, due to the adaptive properties of the body.

We represent (3) in the form of Cauchy. By entering a variable $y=\dot{x}$, we get

$$
\begin{aligned}
& \dot{x}=X(x, y)=y, \\
& \dot{y}=Y(x, y)=-a x-\varepsilon_{0} y-\varepsilon_{1} x^{2} y-\varepsilon_{2} y^{3}+F_{\text {connect }} .
\end{aligned}
$$

Next, we obtain the equations of the periodic trajectory and determine the Lyapunov exponent for assessing the stability of the periodic trajectory depending on the parameters of the system.

System (4) can be represented as

$$
\dot{z}=A(t) z+F(t, z),
$$


where

$$
z=\left[\begin{array}{c}
x \\
\hline y
\end{array}\right], A(t)=A=\left[\begin{array}{c|c}
0 & 1 \\
\hline-a & -\varepsilon_{0}
\end{array}\right], \quad F(t, z)=\left[\begin{array}{c}
0 \\
\hline-\varepsilon_{1} x^{2}-3 \varepsilon_{2} y^{2}+b \cos 2 \omega t
\end{array}\right] .
$$

Solution (5) with initial conditions $z_{0}$ can be found in the form of a series in powers $z_{0}$ with time-dependent coefficients using the method of successive approximations. The first approximation is the solution of the linearized system

$$
\dot{z}^{(1)}=A(t) z^{(1)},
$$

the $m$-th approximation is a solution to the system

$$
\dot{z}^{(m)}=A(t) z^{(m)}+F\left(t, z^{(m-1)}\right) .
$$

Let $\Phi(t)$ is the fundamental matrix of solutions (6), then the solution to system (7) is given by the formula

$$
z^{(m)}(t)=\Phi(t)\left\{z_{0}+\int_{0}^{t} \Phi^{-1}(\tau) F\left(\tau, z^{(m-1)}(\tau)\right) d \tau\right\} .
$$

We define the fundamental matrix of solutions $\Phi(t)$, taking into account the fact that the roots of the characteristic equation are complex conjugate, that is $\lambda_{1,2}=-\varepsilon_{0} / 2 \pm$ $\sqrt{\left(\varepsilon_{0} / 2\right)^{2}-a}=\alpha \pm j \beta$. In this case, $\Phi(t)$ is determined by the expression

$$
\Phi(t)=e^{A t}=e^{\alpha t}\left[\frac{A-\alpha I}{\beta} \sin \beta t+I \cos \beta t\right],
$$

where $I$ is unit matrix size $2 \times 2$. For system (4) we have

$$
e^{A t}=e^{\alpha t}\left[\begin{array}{c|c}
\varepsilon_{0} /(2 \beta) \sin \beta t+\cos \beta t & 1 / \beta \sin \beta t \\
\hline-a / \beta \sin \beta t & -\varepsilon_{0} /(2 \beta) \sin \beta t+\cos \beta t
\end{array}\right] .
$$

When determining the periodic trajectory, we choose the zero initial state. The first approximation of the solution to the system is determined by the expression $z^{(1)}(t)=$ $\Phi(t) z_{0}=0$. Find the second approximation $x^{(2)}(t), y^{(2)}(t)$ :

$$
\begin{gathered}
x^{(2)}(t)=\frac{b}{\beta} \int_{0}^{t} e^{\alpha(t-\tau)} \sin \beta t \cos 2 \omega \tau d \tau, \\
y^{(2)}(t)=-\frac{\varepsilon_{0} b}{2 \beta} \int_{0}^{t} e^{\alpha(t-\tau)} \sin \beta t \cos 2 \omega \tau d \tau+b \int_{0}^{t} e^{\alpha(t-\tau)} \cos \beta t \cos 2 \omega \tau d \tau .
\end{gathered}
$$

Applying the integration formula by parts and trigonometric identities $2 \cos A \cos B=\cos (A-B)+\cos (A+B), \quad 2 \sin A \cos B=\sin (A-B)+\sin (A+B)$, we define:

$$
\begin{gathered}
J_{s}(\gamma)=\int_{0}^{t} e^{\alpha(t-\tau)} \sin (\beta t+\gamma \tau) d \tau=-1 /\left(\gamma^{2}+\alpha^{2}\right)[\gamma \cos (\beta+\gamma) t+ \\
+\alpha \sin (\beta+\gamma) t]+e^{\alpha(t-\tau)} /\left(\gamma^{2}+\alpha^{2}\right)[\gamma \cos \beta t+\alpha \sin \beta t],
\end{gathered}
$$




$$
\begin{gathered}
J_{c}(\gamma)=\int_{0}^{t} e^{\alpha(t-\tau)} \cos (\beta t+\gamma \tau) d \tau=1 /\left(\gamma^{2}+\alpha^{2}\right)[\gamma \sin (\beta+\gamma) t- \\
-\alpha \cos (\beta+\gamma) t]-e^{\alpha(t-\tau)} /\left(\gamma^{2}+\alpha^{2}\right)[\gamma \sin \beta t-\alpha \cos \beta t],
\end{gathered}
$$

where $\gamma$ is an additional parameter entered for ease of integration.

Then (11) takes the form

$$
\begin{gathered}
x^{(2)}(t)=\frac{b}{2 \beta}\left\{J_{s}\left(\gamma_{1}\right)+J_{s}\left(\gamma_{2}\right)\right\} \\
y^{(2)}(t)=-\frac{\varepsilon_{0} b}{4 \beta}\left\{J_{s}\left(\gamma_{1}\right)+J_{s}\left(\gamma_{2}\right)\right\}+\frac{b}{2}\left\{J_{c}\left(\gamma_{1}\right)+J_{c}\left(\gamma_{2}\right)\right\}
\end{gathered}
$$

where $\gamma_{1}=-\beta-2 \omega, \quad \gamma_{2}=-\beta+2 \omega$.

Since $\alpha=\operatorname{Re}\left\{\lambda_{1,2}\right\}<0$, then $\lim _{t \rightarrow \infty} e^{\alpha t}=0$. Expressions for $x^{(2)}(t), \quad y^{(2)}(t)$ include terms containing $e^{\alpha t}$. The equations of the periodic trajectory are obtained, if these terms are not taken into account, i.e. $\varphi_{x}(t)=\left.x^{(2)}(t)\right|_{e^{\alpha t}=0}, \quad \varphi_{y}(t)=\left.y^{(2)}(t)\right|_{e^{\alpha t}=0}$.

After some transformations we get

$$
\varphi_{x}(t)=A \cos 2 \omega t+B \sin 2 \omega t, \quad \varphi_{y}(t)=-2 \omega A \sin 2 \omega t+2 \omega B \cos 2 \omega t,
$$

where the coefficients $A$ and $B$ are determined by the expressions

$$
A=\frac{b\left(a-4 \omega^{2}\right)}{\left(a-4 \omega^{2}\right)^{2}+4 \omega^{2} \varepsilon_{0}^{2}}, \quad B=\frac{2 \omega \varepsilon_{0} b}{\left(a-4 \omega^{2}\right)^{2}+4 \omega^{2} \varepsilon_{0}^{2}} .
$$

Let us analyze the stability of the periodic trajectory (15). The trajectory of the secondorder system has two Lyapunov exponents, one of which is zero, and the other must be negative for the stability of the trajectory. In the two-dimensional case, the Lyapunov exponent can be determined explicitly from the expression

$$
\lambda=\frac{1}{T} \int_{0}^{T}\left[\frac{\partial X\left(\varphi_{x}(t), \varphi_{y}(t)\right)}{\partial x}+\frac{\partial Y\left(\varphi_{x}(t), \varphi_{y}(t)\right)}{\partial y}\right] d t,
$$

where $T$ is a period (for the studied system, the trajectory period is $T=\pi / \omega$ ).

For system (4) $\partial X(x, y) / \partial x=0, \partial Y(x, y) / \partial y=-\varepsilon_{0}-\varepsilon_{1} x^{2}-3 \varepsilon_{2} y^{2}$, where we define $\partial Y\left(\varphi_{x}(t), \varphi_{y}(t)\right) / \partial x$, and then $\lambda$ :

$$
\lambda=-\left[\varepsilon_{0}+\frac{1}{2}\left(\varepsilon_{1}+12 \varepsilon_{2} \omega^{2}\right) \cdot \frac{\left(b^{2}\left(a-4 \omega^{2}\right)\right)^{2}+4 \omega^{2} \varepsilon_{0}^{2} b^{2}}{\left(\left(a-4 \omega^{2}\right)^{2}+4 \omega^{2} \varepsilon_{0}^{2}\right)^{2}}\right] .
$$

We study the Lyapunov exponent $\lambda$ for various values of the parameters $a$ and $b$. We chose the following values of the remaining parameters: $\varepsilon_{1}=-0,3 ; r=0,065 ; \varepsilon_{2}=$ $-3,37 ; \omega=\omega_{0}=6,125[26]$. The results are presented in Table 2 .

In Fig. 2, the phase portrait of the nonautonomous system (4) is presented for the case, which is obtained using the Matlab simulation system. Note that when constructing the phase portrait, the non-autonomous system (4) was reduced to autonomous by introducing an additional phase variable $Q=2 \omega t$.

It can be seen from Fig. 2 that, in addition to a stable periodic trajectory, an unstable periodic trajectory also exists in the system. Trajectories inside an unstable periodic trajectory contract to a stable periodic trajectory represented by equations (15). 
Table 2

The values of the Lyapunov exponent

\begin{tabular}{|c|c|c|c|c|c|c|c|c|c|c|}
\hline$\frac{\mathrm{a}}{\mathrm{b}}$ & 3,0 & 3,1 & 3,2 & 3,3 & 3,4 & 3,5 & 3,6 & 3,7 & 3,8 & 3,9 \\
\hline 0 & $-0,2401$ & $-0,2198$ & $-0,1988$ & $-0,1771$ & $-0,1548$ & $-0,1318$ & $-0,1081$ & $-0,0838$ & $-0,0588$ & $-0,0331$ \\
\hline 5 & $-0,2193$ & $-0,1976$ & $-0,1751$ & $-0,1520$ & $-0,1281$ & $-0,1035$ & $-0,0782$ & $-0,0522$ & $-0,0254$ & 0,0020 \\
\hline$\overline{10}$ & $-0,1963$ & $-0,1730$ & $-0,1489$ & $-0,1241$ & $-0,0985$ & $-0,0721$ & $-0,0450$ & $-0,0171$ & 0,0115 & 0,0409 \\
\hline$\overline{15}$ & $-0,1707$ & $-0,1457$ & $-0,1198$ & $-0,0931$ & $-0,0656$ & $-0,0373$ & $-0,0081$ & 0,0218 & 0,0526 & 0,0842 \\
\hline 20 & $-0,1421$ & $-0,1151$ & $-0,0873$ & $-0,0585$ & $-0,0289$ & 0,0016 & 0,0330 & 0,0653 & 0,0985 & 0,1325 \\
\hline$\overline{25}$ & $-0,1101$ & $-0,0809$ & $-0,0508$ & $-0,0198$ & 0,0122 & 0,0452 & 0,0791 & 0,1140 & 0,1499 & 0,1867 \\
\hline 30 & $-0,0740$ & $-0,0424$ & $-0,0098$ & 0,0238 & 0,0585 & 0,0943 & 0,1311 & 0,1689 & 0,2077 & 0,2476 \\
\hline 35 & $-0,0333$ & 0,0011 & 0,0366 & 0,0732 & 0,1109 & 0,1498 & 0,1898 & 0,2309 & 0,2731 & 0,3165 \\
\hline 40 & 0,0131 & 0,0506 & 0,0893 & 0,1293 & 0,1705 & 0,2129 & 0,2565 & 0,3014 & 0,3475 & 0,3948 \\
\hline 45 & 0,0661 & 0,1072 & 0,1496 & 0,1934 & 0,2386 & 0,2850 & 0,3329 & 0,3820 & 0,4326 & 0,4844 \\
\hline
\end{tabular}

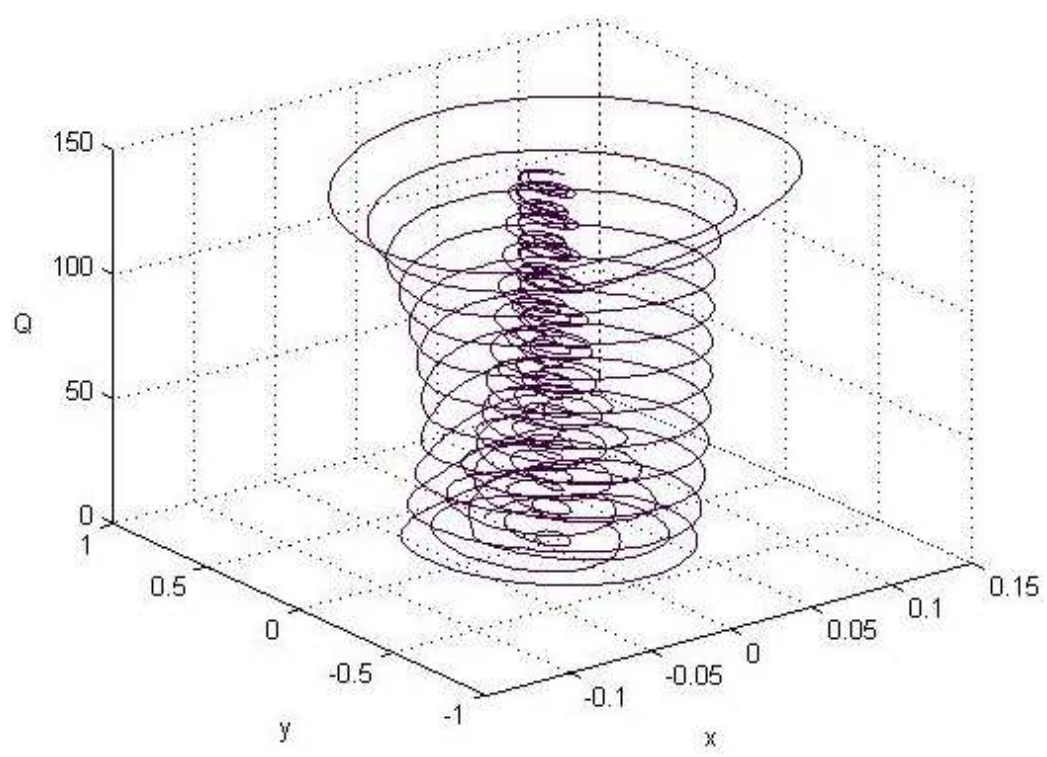

Fig. 2. Phase portrait of the system (4)

Note that for the values of the parameters $a$ and $b$ at which the exponent $\lambda$ approaches zero, the simulation results do not always confirm the conclusions regarding the stability of the periodic trajectory made on the basis of formula (18). In this case, for a more accurate estimation of the exponent $\lambda$, one should find the third approximation of the solution by formula (8), and then determine the equations of the periodic trajectory, assuming $e^{\alpha t}=0$ in the obtained ones $x^{(3)}(t), y^{(3)}(t)$. Next, find the refined expression for $\lambda$ in accordance with (17) and use it.

An analysis of equation (3) with the connection function shows that a stable periodic trajectory which is described by equations (15) appears for some values $F_{\text {connect }}=b \cos 2 \omega t$ of the parameters in the system. The stability of the periodic trajectory can be judged by evaluating the Lyapunov exponent by formula (18). If the parameters included in the connection function are such that the Lyapunov exponent of the periodic trajectory is negative, then this mode of operation of the vessel can be considered normal. When, with a change in the parameters of the connection function, the periodic trajectory of the system approaches the stability boundary, the Lyapunov exponent approaches zero. At 
some parameter values, the periodic trajectory may turn out to be unstable, which is a sign of incorrectness of the obtained form of the soft model.

\section{Identification of Model Parameters}

The identification of the parameters of the obtained models is carried out on the basis of the recorded biosignals of the cardiac cycle in the form of time series. For models of autonomous generators, the initial information is an electrocardiogram. This signal is passed through bandpass filters tuned to the vibration spectra of the corresponding subsystems. For example, to isolate a signal characterizing respiratory activity, the filter passband should be in the range of $0,12-0,4 \mathrm{~Hz}$. The time series obtained after filtration are used to obtain the parameters of the corresponding models.

To identify the parameters of a non-autonomous model of the dynamics of the vessel wall, two signals are used: the signal of the pressure change in the vessel as the input and the sphygmogram as the output.

Parametric identification techniques, including those using regularization, are well developed. Due to their bulkiness, they are not given here.

The obtained hierarchical model of regulation of blood flow in a vessel in the form of differential equations reflects in more detail the state of the cardiovascular system in comparison with the known non-hierarchical models [8, 25].

\section{Conclusion}

A characteristic feature of complex systems is the uncertainty of their internal structure, which prevents the construction of rigid models. The proposed procedure for constructing soft models of complex systems is based on a priori knowledge about the features of the functioning of subsystems and uses the synergistic paradigm of basic models.

A possible implementation of the steps of the proposed procedure is shown by the example of constructing a model of the cardiovascular system.

It should be noted that the main content of the structure of the cardiovascular system is the presentation of the effects of various sources of oscillations on the dynamics of the vessel (object). Many technical systems have a similar structure.

Therefore, this procedure can be used in the construction of models of complex technical systems. In particular, one of the promising areas of application of the proposed procedure is the diagnosis of the state of metal structures under the influence of vibrations formed by various generators.

\section{References}

1. Veshneva I., Singatulin R., Bolshakov A., Chistyakova T., Melnikov L. Model of Formation of the Feedback Channel within Ergatic Systems for Monitoring of Quality of Processes of Formation of Personnel Competences. International Journal for Quality Research, 2015, vol. 9, no. 3, pp. 495-512.

2. Belakhov V.V., Kolodyaznaya V.A., Garabadzhiu A.V., Chistyakova T.B., Smirnov I.A. Application of the Todd-Atherton Synthetic Approach for Chemical Modification of Tetraene Macrolide Antibiotic Lucensomycin. Russian Journal of General Chemistry, 2016, vol. 86, no. 3 , pp. $570-578$. 
3. Veshneva I.V., Chistyakova T.B., Bolshakov A.A. The Status Functions Method for Processing and Interpretation of the Measurement Data of Interactions in the Educational Environment. SPIIRAS Proceedings, 2016. no. 6, pp. 144-166.

4. Buldakov N.S., Buldakova T.I., Suyatinov S.I. Etalon-Photometric Method for Estimation of Tissues Density at X-Ray Images. Progress in Biomedical Optics and Imaging, 2016, vol. 9917, p. 99171Y. DOI: $10.1117 / 12.2229539$

5. Shalizi C.R. Methods and Techniques of Complex Systems Science: An Overview. Boston, Springer, 2006.

6. Chistyakova T.B., Novozhilova I.V. Intelligence Computer Simulators for Elearning of Specialists of Innovative Industrial Enterprises. Proceedings of the XIX International Conference on Soft Computing and Measurements, 2016, pp. 329-332. DOI: $10.1109 /$ SCM.2016.7519772

7. Chistyakova T.B., Razygrayev A.S., Polosin A.N., Araztaganova A.M. Joint Innovative IT Projects in the Field of Production of Polymeric Sheet Materials. 2016 IEEE 5Th Forum Strategic Partnership of Universities and Enterprises of Hi-Tech Branches, Science. Education. Innovations, 2016, pp. 61-64. DOI: 10.1109/IVForum.2016.7835855

8. Bezruchko B.P., Smirnov D.A. Extracting Knowledge from Time Series: An Introduction to Nonlinear Empirical Modelling. Berlin, Springer, 2010.

9. Chistyakova T.B., Polosin A.N. Computer Modelling System of Industrial Extruders with Adjustable Configuration for Polymeric Film Quality Control. 2017 IEEE II International Conference on Control in Technical Systems, 2017, pp. 47-50. DOI: 10.1109/CTSYS.2017.8109485

10. Shen K., Proletarsky A.V., Neusypin K.A. Algorithms of Constructing Models for Compensating Navigation Systems of Unmanned Aerial Vehicles. 2016 International Conference on Robotics and Automation Engineering, 2016, pp. 104-108. DOI: $10.1109 /$ ICRAE.2016.7738798

11. Koval' V.A., Osenin V.N., Suyatinov S.I., Torgashova O.Y. Synthesis of Discrete Controller for Construction of a Distributed Controller of Temperature Conditions of Steam Oil Heater. Journal of Computer and Systems Sciences International, 2011, vol. 50, no. 4, pp. 638-653. DOI: $10.1134 /$ S1064230711040125

12. Xu P.C. Differential Phase Space Reconstructed for Chaotic Time Series. Applied Mathematical Modelling, 2009, vol. 33, pp. 999-1013.

13. Buldakova T.I., Suyatinov S.I. Reconstruction Method for Data Protection in Telemedicine Systems. Progress in Biomedical Optics and Imaging, 2014, vol. 9448, p. 94481U. DOI: $10.1117 / 12.2180644$

14. Huanfei Ma, Siyang Leng, Luonan Chen. Data-Based Prediction and Causality Inference of Nonlinear Dynamics. Science Placecountry-Regionchina Mathematics, 2017, vol. 60, pp. 403-420. DOI: 10.1007/s11425-000-0000-0

15. Tronci St., Giona M., Baratti R. Reconstruction of Chaotic Time Series by Neural Models: a Case Study. Neurocomputing, 2003, vol. 55, pp. 581-591.

16. Huanfei Ma, Aihara K., Luonan Chen. Detecting Causality from Nonlinear Dynamics with Short-Term Time Series. Scientific Reports, 2014, vol. 4, p. 7464.

17. Pecora L.M., Moniz L., Nichols J., Carroll T.L. A Unified Approach to Attractor Reconstruction. An Interdisciplinary Journal of Nonlinear Science, 2007, vol. 17, no. 1, pp. 1-9. 
18. Basarab M.A., Konnova N.S., Basarab D.A., Matsievskiy D.D. Digital Signal Processing of the Doppler Blood Flow Meter Using the Methods of Nonlinear Dynamics. Progress in Electromagnetics Research Symposium, 2017, pp. 1715-1720. DOI: 10.1109/PIERS.2017.8262026

19. Haken H. Synergetics: An Introduction. Berlin, Springer, 1983.

20. Stefanovska A. Coupled Oscillators: Complex but Not Complicated Cardiovascular and Brain Interactions. IEEE Engineering in Medicine and Biology Magazine, 2007, vol. 26, no. 6, pp. 25-29.

21. Mehregan M.R., Hosseinzadeh M., Kazemi A. An Application of Soft System Methodology. Procedia - Social and Behavioral Sciences, 2012, vol. 41, pp. 426-433. DOI: $10.1016 /$ j.sbspro.2012.04.051

22. Gupta P., Kulkarni N. An Introduction of Soft Computing Approach Over Hard Computing. International Journal of Latest Trends in Engineering and Technology, 2013, vol. 3, no. 1, pp. 254-258.

23. Sivanandam S.N., Deepa S.N. Principles of Soft Computing. N.Y., Wiley, 2011.

24. Stefanovska A., Lotric M.B., Strle S., Haken H. The Cardiovascular System as Coupled Oscillators? Physiological Measurement, 2001, vol. 22, pp. 535-550.

25. Silvani A., Magosso E., Bastianini S., Lenzi P., Ursino M. Mathematical Modelling of Cardiovascular Coupling: Central Autonomic Commands and Baroreflex Control. Autonomic Neuroscience: Basic and Clinical, 2011, vol. 162, pp. 66-71. DOI: 10.1016/j.autneu.2011.04.003

26. Buldakova T.I., Suyatinov S.I. Registration and Identification of Pulse Signal for Medical Diagnostics. The International Society for Optical Engineering, 2002, vol. 4707, pp. 343-350.

27. Suyatinov S.I. Criteria and Method for Assessing the Functional State of a Human Operator in a Complex Organizational and Technical System. Global Smart Industry Conference, 2018, pp. 1-6. DOI: 10.1109/GloSIC.2018.8570088

Received September 10, 2019

\section{ПРОЦЕДУРА ПОСТРОЕНИЯ МЯГКИХ МОДЕЛЕЙ СЛОЖКЫХ СИСТЕМ ПО ВРЕМЕННЫМ РЯДАМ}

C.И. Суятинов, Московский государственный технический университет им. Н.Э. Баумана, г. Москва, Российская Федерация

Рассмотрена проблема создания моделей сложных систем для оценки их состояния. Приведен анализ подходов к построению диагностических моделей и отмечены их особенности. Для сложной системы, имеющей иерархическую структуру, предложена процедура конструирования по скалярному временному ряду моделей для оценки ее состояния. При этом каждый иерархический уровень описывается дифференциальным уравнением с сосредоточенными параметрами. В основу процедуры положена концепция мягкого моделирования. Работоспособность предложенной процедуры продемонстрирована на примере конструирования модели для оценки состояния сложной системы регуляции сердечного ритма.

Ключевые слова: сложная система; мягкое моделирование; базовые модели; сердечно-сосудистая система. 


\section{Литература}

1. Veshneva, I. Model of Formation of the Feedback Channel within Ergatic Systems for Monitoring of Quality of Processes of Formation of Personnel Competences / I. Veshneva, R. Singatulin, A. Bolshakov, T. Chistyakova, L. Melnikov // International Journal for Quality Research. - 2015. - V. 9, № 3. - P. 495-512.

2. Belakhov, V.V. Application of the Todd-Atherton Synthetic Approach for Chemical Modification of Tetraene Macrolide Antibiotic Lucensomycin / V.V. Belakhov, V.A. Kolodyaznaya, A.V. Garabadzhiu, T.B. Chistyakova, I.A. Smirnov // Russian Journal of General Chemistry. - 2016. - V. 86, № 3. - P. 570-578.

3. Veshneva, I.V. The Status Functions Method for Processing and Interpretation of the Measurement Data of Interactions in the Educational Environment / I.V. Veshneva, T.B. Chistyakova, A.A. Bolshakov // SPIIRAS Proceedings. - 2016. - № 6. - P. 144-166.

4. Buldakov, N.S. Etalon-Photometric Method For Estimation of Tissues Density at X-Ray Images / N.S. Buldakov, T.I. Buldakova, S.I. Suyatinov // Progress in Biomedical Optics and Imaging - Proceedings of SPIE. - 2016. - V. 9917. - Article ID: 99171Y. DOI: $10.1117 / 12.2229539$

5. Shalizi, C.R. Methods and Techniques of Complex Systems Science: An Overview / C.R. Shalizi. - Boston: Springer, 2006.

6. Chistyakova, T.B. Intelligence Computer Simulators for Elearning of Specialists of Innovative Industrial Enterprises / T.B. Chistyakova, I.V. Novozhilova // Proceedings of the XIX International Conference on Soft Computing and Measurements. - 2016. - P. 329-332.

7. Chistyakova, T.B. Joint Innovative IT Projects in the Field of Production of Polymeric Sheet Materials / T.B. Chistyakova, A.S. Razygrayev, A.N. Polosin, A.M. Araztaganova // IEEE 5th Forum Strategic Partnership Of Universities And Enterprises of Hi-Tech Branches, Science. Education. Innovations. - 2016. - P. 61-64.

8. Bezruchko, B.P. Extracting Knowledge from Time Series: An Introduction to Nonlinear Empirical Modelling / B.P. Bezruchko, D.A. Smirnov. - Berlin: Springer, 2010.

9. Chistyakova, T.B. Computer Modelling System of Industrial Extruders with Adjustable Configuration for Polymeric Film Quality Control / T.B. Chistyakova, A.N. Polosin // 2017 IEEE II International Conference on Control in Technical Systems. - 2017. - P. 47-50.

10. Shen, K. Algorithms of Constructing Models for Compensating Navigation Systems of Unmanned Aerial Vehicles / K. Shen, A.V. Proletarsky, K.A. Neusypin // 2016 International Conference on Robotics and Automation Engineering. - 2016. - P. 104-108.

11. Koval', V.A. Synthesis of Discrete Controller for Construction of a Distributed Controller of Temperature Conditions of Steam Oil Heater / V.A. Koval', V.N. Osenin, S.I. Suyatinov, O.Y. Torgashova // Journal of Computer and Systems Sciences International. - 2011. - V. 50, № 4. - P. 638-653.

12. Xu, P.C. Differential Phase Space Reconstructed for Chaotic Time Series / P.C. Xu // Applied Mathematical Modelling. - 2009. - V. 33, № 2. - P. 999-1013.

13. Buldakova, T.I., Suyatinov, S.I. Reconstruction Method for Data Protection in Telemedicine Systems / T.I. Buldakova, S.I. Suyatinov // Progress in Biomedical Optics and Imaging. 2014. - V. 9448, Article ID: 94481 U.

14. Huanfei Ma. Data-Based Prediction and Causality Inference of Nonlinear Dynamics / Huanfei Ma, Siyang Leng, Luonan Chen // Science China Mathematics. - 2017. - V. 60. - P. 406-420.

15. Tronci St. Reconstruction of Chaotic Time Series by Neural Models: a Case Study / St. Tronci, M. Giona, R. Baratti // Neurocomputing. - 2003. - V. 55. - P. 581-591. 
16. Huanfei Ma. Detecting Causality from Nonlinear Dynamics with Short-term Time Series / Ma Huanfei, K. Aihara, Luonan Chen // Scientific Reports. - 2014. - V. 4, № 7464 . P. 7464 .

17. Pecora, L.M. A Unified Approach to Attractor Reconstruction / L.M. Pecora, L. Moniz, J. Nichols, T.L. Carroll // An Interdisciplinary Journal of Nonlinear Science. - 2007. - V. 17, № 1. - P. 1-9.

18. Basarab, M.A. Digital Signal Processing of the Doppler Blood Flow Meter Using the Methods of Nonlinear Dynamics / M.A. Basarab, N.S. Konnova, D.A. Basarab, D.D. Matsievskiy // Progress in Electromagnetics Research Symposium. - 2017. - P. 1715-1720.

19. Haken, H. Synergetics: An Introduction / H. Haken. - Berlin: Springer, 1983.

20. Stefanovska, A. Coupled Oscillators: Complex but Not Complicated Cardiovascular and Brain Interactions / A. Stefanovska // IEEE Engineering in Medicine and Biology Magazine. - 2007. - V. 26, № 6. - P. 25-29.

21. Mehregan, M.R. An Application of Soft System Methodology / M.R. Mehregan, M. Hosseinzadeh, A. Kazemi // Procedia - Social and Behavioral Sciences. - 2012. - V. 41. - P. 426-433.

22. Gupta, P. An Introduction of Soft Computing Approach over Hard Computing / P. Gupta, N. Kulkarni // International Journal of Latest Trends in Engineering and Technology. 2013. - V. 3, № 1. - P. 254-258.

23. Sivanandam, S.N. Principles of Soft Computing / S.N. Sivanandam, S.N. Deepa. - N.Y.: Wiley, 2011.

24. Stefanovska, A. The Cardiovascular System as Coupled Oscillators? / A. Stefanovska, M.B. Lotric, S. Strle, H. Haken // Physiological Measurement. - 2001. - V. 22. - P. 535-550.

25. Silvani, A. Mathematical Modelling of Cardiovascular Coupling: Central Autonomic Commands and Baroreflex Control / A. Silvani, E. Magosso, S. Bastianini, P. Lenzi, M. Ursino // Autonomic Neuroscience: Basic and Clinical. - 2011. - V. 162. - P. 66-71.

26. Buldakova, T.I. Registration and Identification of Pulse Signal for Medical Diagnostics / T.I. Buldakova, S.I. Suyatinov // The International Society for Optical Engineering. 2002. - V. 4707, № 48. - P. 343-350.

27. Suyatinov, S.I. Criteria and Method for Assessing the Functional State of a Human Operator in a Complex Organizational and Technical System / S.I. Suyatinov // Global Smart Industry Conference. - 2018. - P. 1-6.

Сергей Игоревич Суятинов, кандидат технических наук, доцент, кафедра «Системы автоматического управления», Московский государственный технический университет им. Н.Э. Баумана (г. Москва, Российская Федерация), ssi@bmstu.ru.

Поступила в редакцию 10 сентября 2019 г. 